\title{
Development of a Simple Hydroponic Assay to Study Vertical and Horizontal Resistance of Soybean and Pathotypes of Phytophthora sojae
}

A. Lebreton, C. Labbé, and M. De Ronne, Département de Phytologie, Université Laval, Québec, Québec, G1V 0A6, Canada; A. G. Xue, Ottawa Research and Development Centre, Agriculture and Agri-Food Canada, Ottawa, Ontario K1A 0C6, Canada; G. Marchand, Harrow Research and Development Centre, Agriculture and Agri-Food Canada, Harrow, Ontario NOR 1G0, Canada; and R. R. Bélanger, ${ }^{\dagger}$ Département de Phytologie, Université Laval, Québec, Québec, G1V 0A6, Canada

\begin{abstract}
Phytophthora root rot, caused by Phytophthora sojae, is one of the most damaging diseases of soybean and the introgression of Rps (Resistance to $P$. sojae) genes into elite soybean lines is arguably the best way to manage this disease. Current bioassays to phenotype the gene-for-gene relationship are hampered with respect to reproducibility and long-term stability of isolates, and do not accurately predict horizontal resistance individually. The aim of our study was to investigate a new way of phenotyping $P$. sojae isolates and vertical and horizontal resistance in soybean that relies on zoospores inoculated directly into a hydroponic system. Inoculation of $P$. sojae isolates against a set of eight differentials accurately and

reproducibly identified pathotypes over a period of two years. When applied to test vertical resistance of soybean lines with known and unknown $R p s$ genes, the bioassay relied on plant dry weight to correctly identify all genes. In addition, simultaneous inoculations of three $P$. sojae isolates, collectively carrying eight major virulence factors against 64 soybean lines with known and unknown levels of horizontal resistance, separated the plants into five distinct groups of root rot, allowing the discrimination of lines with various degrees of partial resistance. Based on those results, this bioassay offers several advantages in facilitating efforts in breeding soybean for $P$. sojae resistance and in identifying virulence factors in $P$. sojae.
\end{abstract}

As a result of its intensified production, soybean has become the target of many pathogens and pests affecting yield. Among them, Phytophthora root rot (PRR) caused by the oomycete Phytophthora sojae M. J. Kaufmann \& J. W. Gerdemann is one of the most important and widespread pathogens leading to annual losses estimated at well over one billion dollars worldwide (Tyler 2007). This pathogen is particularly devastating because it can attack plants at all stages of development causing pre- and postemergence damping-off, leaf chlorosis or wilting, and root rot often leading to death of seedlings and mature plants (Schmitthenner 2000).

Since its emergence and first identification in the 1950s (Schmitthenner 1985), the occurrence of PRR is now reported in all soybean-producing regions. Many efforts have been undertaken to manage the expansion of the disease. Among the different strategies proposed for this purpose over the years, including modification of cultural practices (Workneh et al. 1998; Schmitthenner 1985; Zhang and Xue 2010), use of chemicals (Guy et al. 1989), inorganic elements (Sugimoto et al. 2005; Sugimoto et al. 2009; Guérin et al. 2014), or biological control (Osburn et al. 1995; Hsu and Lockwood 1984; Xiao et al. 2002), one of the most efficient and reliable ways to prevent PRR remains through genetic resistance. Two main types of resistance have been described in soybean: horizontal and vertical resistance (Sugimoto et al. 2012). Horizontal, or partial resistance is quantitatively inherited and conditioned by quantitative trait loci (QTLs). The exact number of genes involved and their interaction are not yet known, and effective QTLs can vary from one study to the next (Schneider et al. 2016). Plants with partial resistance are reported to have broad-spectrum resistance, and so are less colonized or affected, regardless of which $P$. sojae pathotypes are present in the field. Vertical, or total, resistance leads to complete protection against specific pathotypes of $P$. sojae owing to the presence of single resistance

${ }^{\dagger}$ Corresponding author: Richard Bélanger;

E-mail: richard.belanger@fsaa.ulaval.ca

*The $\boldsymbol{e}$-Xtra logo stands for "electronic extra" and indicates that two supplementary figures are published online.

Accepted for publication 31 August 2017.

() 2018 The American Phytopathological Society genes called "resistance to Phytophthora sojae" (Rps) genes, which were first reported in 1957 (Bernard et al. 1957). Currently, 28 such genes have been characterized from Rps 1 to Rps 12 and their different alleles, and others such as Rps Yu25, Rps YD25, RpsWaseshiroge, RpsYD29, RpsUN1, Rps YB30, RpsZS18, RpsSN10, RpsUN2, and RpsJS have recently been reported (Sahoo et al. 2017). Additional forms of resistance can be encountered in soybean including root resistance in the specific case of Rps2, which is reported to confer incomplete resistance (Mideros et al. 2007).

Currently, the use of Rps genes is still a commonly exploited method for the management of PRR through their introgression into soybean cultivars. A single Rps gene, Rpsla, was first widely and successfully deployed in commercial cultivars, but this approach finally led to genetically uniform crops in terms of resistance (Dorrance 2013; Sugimoto et al. 2012). As a result, the high selection pressure exerted on $P$. sojae contributed to the emergence of new pathotypes able to adapt and overcome this Rps gene within 8 to 15 years (Schmitthenner et al. 1994). Thus, among all reported Rps genes, Rps 1a, 1c, 1k, 3a, 6, and 7 have successively been introgressed in commercial lines (Abeysekara et al. 2016; Anderson and Buzzell 1992). This process based on a "boom and bust cycle" is still ongoing, leading to an arms race between breeders, on the one hand, and P. sojae on the other (McDonald and Linde 2002). In this context, breeders need an effective, fast, and reliable way to identify resistance genes and the corresponding phenotypes in order to guide their choice of resistant cultivars carrying the Rps genes associated to the specific virulence factors of $P$. sojae present in a given area of production.

Isolates of $P$. sojae collected in the field have been originally defined as a race with corresponding pathotypes based on the virulence reactions that each isolate had on the isolines of a set of host differentials carrying a unique and specific resistance gene (Dorrance et al. 2004). However, 55 races had been inventoried by the mid-2000s, so this "race nomenclature" was abandoned owing to the increasing number and complexity of isolates and the "pathotype nomenclature" adopted (Dorrance 2013). Phytophthora sojae isolates are now characterized by their pathotypes, i.e., virulence factors, referring to the compatible interactions obtained after inoculation of the differentials.

In order to properly assess the pathotypes of a given isolate, several phenotyping methods have been developed and proposed (Haas and Buzzell 1976; Kilen and Keeling 1977; Morrison and Thorne 1978; Pazdernik et al. 1997; Wagner and Wilkinson 1992; Ward et al. 1979). 
Over the years, the hypocotyl inoculation test has become the standard reference test, because of its ease of use (Dorrance et al. 2008). Briefly, stems of plantlets from the set of differentials are wounded and inoculated with a mycelial slurry of an isolate of $P$. sojae. If a spreading dark lesion forms following inoculation on a differential carrying a specific $R p s$ gene, then the corresponding virulence factor is associated with the isolate. Conversely, it is possible to determine if a soybean cultivar carries a specific Rps gene by inoculating it with an isolate carrying the corresponding virulence factor. More recently, Jiang et al. (2017) proposed an improved assay that involves mixing the mycelium slurry into the soil, thereby eliminating the need to wound the plantlets, although inconsistencies were observed in avr-Rps gene interactions.

As convenient as the hypocotyl inoculation method is, it has limitations that have often frustrated breeders and plant pathologists following the identification of false positives or negatives. For instance, the inoculation method bypasses the root system and the natural infection process by zoospores. This can prevent the observation of partial or of root resistance controlled by Rps 2 , for instance. In an exhaustive analysis of $P$. sojae isolates found in Ohio, Schmitthenner et al. (1994) reported frequent changes in the virulence patterns of isolates with the hypocotyl test following retesting or long-term storage.

When testing for partial or horizontal resistance in soybean cultivars, additional phenotyping methods are required to establish the complete resistance pattern of a cultivar. Some researchers favor field tests (McBlain et al. 1991), but a more common method remains the inoculum layer test conducted in a greenhouse (Dorrance et al. 2008) because more parameters can be controlled. However, fields tests are highly variable and difficult to reproduce with the same conditions, and the layer test is a cumbersome procedure because it is necessary to first proceed with a hypocotyl inoculation test to ensure a compatible interaction should be used that will not hide the response with any Rps gene (Stewart and Robertson 2012).

In a recent study of the prophylactic role of silicon against $P$. sojae, Guérin et al. (2014) proposed the use of a hydroponic bioassay to infect soybean plants. While their study did not look at the gene-forgene interaction between soybean and $P$. sojae, the proposed assay had the distinct advantage of relying on zoospores for inoculation of the root system. Conceptually, it could thus overcome the limitations associated with the hypocotyl assay or other assays relying on mycelium slurry, and could further provide more versatility by identifying both complete and partial resistance in soybean cultivars. In this context, the specific objectives of this study were to evaluate the reliability of a hydroponic bioassay in (i) identifying $P$. sojae pathotypes used to challenge a set of soybean differentials; (ii) identifying Rps genes in soybean cultivars following inoculation with different pathotypes; (iii) identifying the same interactions between isolates and cultivars over repeated subcultures; and (iv) discriminating soybean cultivars for partial resistance following inoculation with a complex of $P$. sojae isolates. In addition, attempts were made to assess the reliability of the assay through a simplified approach using miniature hydroponic systems (Supplementary Fig. S2).

\section{Materials and Methods}

Hydroponic conditions. For all experiments in the recirculating hydroponic systems, soybean seeds were germinated in Petri dishes on moistened filter paper in darkness at room temperature. After five days, when radicles and hypocotyls were well developed, seedlings were transferred to plastic pots filled with rockwool (Hydroculture Guy Dionne Inc., Quebec) in a hydroponic system in the greenhouse. Briefly, each unit included a magnetic drive pump (950 liters/h), a 60-liter tank, and two plastic troughs (Supplementary Fig. S1). Roots were immersed with the nutrient solution through a dripping system for 30 min every hour. The nutrient solution used was modified from Arsenault-Labrecque et al. (2012) where salts were separated into three different solutions: macronutrients $\left(\mathrm{KNO}_{3}, \mathrm{KCl}, \mathrm{CaCl}_{2}\right.$, $\mathrm{K}_{2} \mathrm{HPO}_{4}, \mathrm{MgSO}_{4} \cdot 7 \mathrm{H}_{2} \mathrm{O}, \mathrm{MgCl}_{2} \cdot 6 \mathrm{H}_{2} \mathrm{O}$ ) were prepared as a $30 \times$ solution; micronutrients $\left(\mathrm{H}_{3} \mathrm{BO}_{3}, \mathrm{MnSO}_{4} \cdot \mathrm{H}_{2} \mathrm{O}, \mathrm{CuSO}_{4} \cdot 5 \mathrm{H}_{2} \mathrm{O}\right.$, $\left.\mathrm{ZnSO}_{4} \cdot 7 \mathrm{H}_{2} \mathrm{O}, \mathrm{NaMoO}_{4} \cdot 2 \mathrm{H}_{2} \mathrm{O}, \mathrm{Co}\left(\mathrm{NO}_{3}\right)_{2} \cdot 6 \mathrm{H}_{2} \mathrm{O}\right)$ as a $5,000 \times$ solution; and FeNa-EDTA $(13.2 \%)$ was separately prepared as a 3,000× solution.
A 50-liter solution containing 2 liters of macronutrients, $12 \mathrm{ml}$ of micronutrients, and $19.8 \mathrm{ml}$ of Fe-EDTA, and adjusted to $\mathrm{pH} 6.5$, was added to 60-liter black polystyrene tanks (Hydroculture Guy Dionne Inc., Montréal, Quebec) so that a complete solution was distributed to growing plants. All experiments were conducted in a greenhouse with controlled parameters: temperature maintained at 20 to $25^{\circ} \mathrm{C}, 70 \%$ relative humidity, and a 14-h photoperiod.

Zoospore inoculation. Zoospore production was based on the methods of Eye et al. (1978) and Guérin et al. (2014) with some modifications. Ten plates of V8 (20\%)-phytagel culture [200 ml clarified V8, 4 g phytagel (Sigma-Aldrich, Saint Louis, MO), and $800 \mathrm{ml}$ distilled water] were used per isolate of $P$. sojae. Sixty mycelial plugs ( $9 \mathrm{~mm}$ diameter) from six-day-old cultures were immersed in a Petri dish $(150 \times 150 \mathrm{~mm})$ in $60 \mathrm{ml}$ of sterile tap water added to $15 \mathrm{ml}$ of sterile Agromix soil extract (Fafard, Saint Bonaventure, Québec). Five plates of that mixture were sealed with Parafilm and gently shaken on an orbital shaker at room temperature for $18 \mathrm{~h}$. Zoospores were observed with a microscope, and swimming and encysted zoospores were counted using the method of Ko et al. (1973). A 1- $\mu$ l drop was placed on a glass slide, and observed under a $100 \times$ microscopic field. Ten observations were used to determine the zoospore concentration in suspension, and cultures ranging between $10^{3}$ to $10^{4}$ zoospores/ml were used for inoculation. Five plates of mycelial plugs provided $\sim 350 \mathrm{ml}$ of zoospore suspension that were collected in a 500-ml bottle and added directly to the nutrient solution in 60 liter tanks. The spore suspension or an equal volume of water for control plants was added to the tanks 7 days after transfer of seedlings to the hydroponic system.

Phytophthora sojae isolates. All $P$. sojae isolates used in this study were obtained from the bank collected and maintained by A. Xue at AAFC, Ottawa, and were selected on the basis of their predominance in Ontario fields and their potential virulence patterns against the most common Rps genes used in commercial lines. These isolates were originally characterized by the hypocotyl inoculation test on a panel of soybean differentials. They were maintained on V8 phytagel. Isolates used in this study and their corresponding pathotypes are presented in Table 1.

Identification of $\boldsymbol{P}$. sojae pathotypes. In order to determine if the hydroponic bioassay was reliable for the identification of pathotypes in $P$. sojae isolates, a set of eight common soybean differentials was used. All of these were isolines with a 'Williams' or 'Harosoy' genetic background. The list of differentials and their respective Rps genes are presented in Table 2. For inoculation, $P$. sojae isolates Ont-7-1 and Ont-42-1 were used (Table 2). In addition, the differentials were tested against a mixture of all three isolates to assess if the inoculation led to infection in all possible compatible interactions.

Stability over repeated subcultures. In order to assess if the virulence patterns of isolates Ont-7-1 and Ont-42-1 changed in the hydroponic assay following long-term storage and repeated testing, Williams and Haro15 (Rps1k) were routinely tested over the course of two years with cultures collected from a long-term storage tube maintained at room temperature. The interactions were tested with four plants for each soybean line in the same hydroponic conditions as described above. Tests were conducted five times (winter and summer 2015, winter and summer 2016 and winter 2017) over a period of two years, and the interactions were scored as resistant or susceptible.

Table 1. List and characteristics of Phytophthora sojae isolates used in this study

\begin{tabular}{lcll}
\hline Isolate & DAOM $^{\mathbf{a}}$ & Pathotype (vir factors) & \multicolumn{1}{c}{ Origin } \\
\hline Ont-7-1 & 243215 & 1a, 1c, 1d, 7 & Vars (Ontario, 2012) \\
Ont-42-1 & 243223 & 1a, 1b, 1c, (1d), 1k, 7 & Tilbury (Ontario, 2012) \\
Amand-1 & 238913 & 1a, 3a, 6, 7 & Harrow (Ontario, 2007) \\
\hline
\end{tabular}

${ }^{a}$ Department of Agriculture, Ottawa, Mycology (DAOM); numbers under which these isolates have been deposited in the Canadian Collection of Fungal Cultures.

b Ont-42-1 was originally classified as missing the virulence factor $1 \mathrm{~d}$. 
Identification of Rps genes in commercial soybean lines. For the identification of Rps genes conditioning vertical resistance, seeds from 10 soybean lines were graciously provided by Prograin Semences Inc. (Saint Césaire, Québec). Each line was only identified by a number (1 to 10) with no information with respect to genetic background or presence of Rps genes at the time of testing other than the fact that they only contained Rps genes associated with the pathotypes of the isolates tested. Each line was tested against three isolates of $P$. sojae, (Ont-7-1, Ont-42-1, and Amand-1) and the experiment was repeated. For control purposes, plants from Williams with no known vertical resistance to $P$. sojae as well as plants from Haro15 carrying Rps $1 \mathrm{k}$ were used. At the end of the experiments, interactions were scored and Rps genes predicted as described below and compared with Rps genes background revealed by the company.

Identification of partial (horizontal resistance) in soybean lines. Given the difficulties and often the need to run two or more bioassays to identify horizontal resistance to $P$. sojae in soybean lines, the hydroponic assay was used to test a number of soybean lines with different or unknown properties in terms of partial resistance. These included: 'PI449459', reported as partially resistant (Jia and Kurle 2008); 'L494091' (Rps2), which develops an intermediate response with the hypocotyl wounding test (Mideros et al. 2007); 'Misty', known for its susceptibility; 'Jack', reported to be partially resistant; 'Conrad', reported for its high partial resistance (Sugimoto et al. 2012); and 59 lines (L1-L59) provided by Prograin Semences Inc., la Coop Fédérée and Syngenta Canada with unknown levels of partial resistance. Inoculations were made with a mixture of $P$. sojae isolates Ont-7-1, Ont-42-1, and Amand-1, which overcome all eight common Rps genes. For control purposes, Haro15 (Rpslk) and Williams (no known resistance) were used.

Data analysis and phenotyping. For each experiment, the protocol included four $314 \times 14 \mathrm{~cm}$ plastic troughs (Hydroculture Guy Dionne Inc., Québec) supplied by two 60-liter containers, with each trough containing 20 plants. For each soybean line tested, four plants per treatment per repetition were used. The cultivars were randomized in each trough of each system. The root system and aerial portion of each plant were photographed one week after inoculation, and weekly thereafter until the end of the experiment ( 21 days post inoculation (dpi)). Plants were dried at $50^{\circ} \mathrm{C}$ for $24 \mathrm{~h}$ and weighed. Disease was scored based on the average dry weight of plants. Means and standard errors were calculated from four separate plants. Statistical analyses were performed with JMP12 software comparing each inoculated cultivar with controls by performing Dunnett's test $(P<0.05)$.

Hydroponic assays in miniature systems. Because the recirculating system is demanding in terms of space, costs, and human resources, the hydroponic assays were transferred into plastic containers to determine if it could be scaled down with reproducible results. For this purpose, 10-liter containers (Rubbermaid, Atlanta, GA) were fitted with a 4-cm thick styrofoam sheet (Dow Styrofoam, Home Depot) in which $305-\mathrm{cm}$ holes were drilled to support 5-cm hydroponic baskets (Hydroculture Guy Dionne, Québec) (Supplementary Figure S2). Soybean seeds of the eight soybean differentials (Table 2) were sown in sterile vermiculite in a tray kept at room temperature and darkness for three days. Trays were removed from darkness to light two days before transfer to the hydroponic solution. Five-day-old seedlings were transferred to rockwool (Gro-Wool

Table 2. Soybean differentials used for phenotyping assay against isolates of Phytophthora sojae

\begin{tabular}{llcl}
\hline Rps & Cultivar & Background & \multicolumn{1}{c}{ Source of Rps gene } \\
\hline Rps1a & L75-6141 & Williams & Union \\
Rps1b & L77-1863 & Williams & Harrell \\
Rps1c & L75-3735 & Williams & Lee68 \\
Rps1d, Rps7 & Haro1672 & Harosoy & PI103091 (1d), Harosoy (7) \\
Rps1k & Haro15 & Harosoy & Kingwa \\
Rps3a & L83-570 & Williams & PI86972-1 \\
Rps6 & L89-1581 & Williams & Altona \\
Rps7 & L93-3258 & Williams & Harosoy \\
\hline
\end{tabular}

absorbent granulate, Grodan, Kingsville, ON, Canada) in each of the 30 small baskets fitted into the styrofoam sheet. The 10-liter nutrient

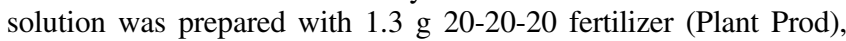
$1.5 \mathrm{~g}$ Epsom salt $\left(\mathrm{MgSO}_{4} \cdot 7 \mathrm{H}_{2} \mathrm{O}\right)$ and $3 \mathrm{ml} \mathrm{FeNa-EDTA} 3000 \mathrm{X}$. For inoculation, isolate Ont-42-1 was used for comparative purposes with the experiments in recirculating solutions. The inoculum $\left(1 \times 10^{3}\right.$ zoospores $/ \mathrm{ml}$ ) was prepared as described previously using sixty mycelial plugs from one plate of six-day-old cultures. A 50-ml zoospore suspension was added directly into the nutrient solution. Phenotypic responses of resistance or susceptibility were recorded at $14 \mathrm{dpi}$. In each experiment, three plants per differential were tested and the experiment was repeated. Williams was used as a control.

In parallel, the miniature system was tested for the detection of horizontal resistance with Harosoy and Misty, PI449459 as a reported source of horizontal resistance, and 'QS5091.50J', an early maturity cultivar provided by Dr. L. O'Donoughue from CEROM (Beloeil, Quebec), as an unknown. Plants were grown as described above and inoculated with a mixture of the three isolates Ont-7-1, Ont-42-1, and Amand-1 to nullify the expression of vertical resistance and phenotypes for horizontal resistance were quantified as dry weight at $21 \mathrm{dpi}$.

\section{Results}

Identification of $\boldsymbol{P}$. sojae pathotypes. As early as $7 \mathrm{dpi}$, roots of control plants cv Williams presented the first symptoms of infection with necrotic lesions on secondary roots. These symptoms progressed over the course of the experiments on plants of cv Williams and of other compatible (susceptible) lines. More specifically, susceptible cultivars displayed a wide range of symptoms such as brown discoloration of the main root, black crowns, reduced root systems and even death of plants, even though the hydroponic solution tended to delay mortality in spite of a heavily infected root system (Fig. 1A and C). By contrast, in the case of incompatible (resistant) interactions, roots were free of obvious symptoms and similar to roots of noninoculated control plants (Fig. 1A and C). The simultaneous presence of incompatible and compatible interactions in the same system confirmed the discriminating potential of the hydroponic bioassay and thereby eliminated the possibility of false positives or negatives. Based on these phenotypic observations, pathotypes of the two isolates were easily determined. Moreover, dry weights of aerial part were recorded and confirmed the visual observations. Susceptible plants were consistently significantly lighter than the controls, while resistant plants had either similar or, in some cases, higher weights than the controls (Fig. 1B and D). In all cases, plant dry weights corroborated the visual observations in terms of defining compatible and incompatible interactions. Of interest, both interactions with Rps 1d resulted in an expected necrotic root system that was not always associated with symptoms on aerial parts of the plants (Fig. 1A and C).

Interestingly, when the differentials were inoculated with a mixture of all three isolates, all plants developed a compatible interaction, thus confirming that simultaneous inoculations with several isolates could lead to expression of all virulence factors (data not shown).

Identification of Rps genes in commercial soybean lines. As with the differentials, the 10 commercial soybean lines were observed throughout the experiments for symptoms of infection and dry weights recorded at the end. Different interactions were evident based on average dry weights (Fig. 2), which allowed conclusions to be drawn about the specific absence/presence of $R p s$ genes. Firstly, cvs $1,8,9$ and 10 were only susceptible to isolate Amand-1, while cvs 6 and 7 were only resistant to the same isolate. For their part, cvs 3 and 5 showed a compatible interaction only with isolate Ont42-1. Finally, two extreme profiles were noted with cvs 2 and 4, with the former being susceptible to all three isolates, and the latter resistant to all three. Based on dry weight data, we were able to propose a compatibility table (resistant or susceptible) for all cultivars against all pathotypes tested, and to predict which Rps genes each cultivar carries (Table 3). Interestingly, in most cases, plants of an incompatible interaction had a higher dry weight than control plants, which facilitated their classification (Fig. 2). 
Stability over repeated subcultures. Owing to the fact that $P$. sojae isolates will often present different virulence patterns following retesting and storage with the hypocotyl assay, we repeated experiments over two years following multiple subcultures of two isolates to observe if virulence patterns changed in hydroponics. Over the two-year period where the experiments were repeated five times, plants of Williams (rps) presented a susceptible reaction regardless of the isolate used, while those of Haro15 (Rps $1 \mathrm{k})$ presented an expected resistant reaction with isolate Ont-7-1 and a susceptible one with isolate Ont-42-1. Figure 3 presents the typical phenotypes obtained after the first and last experiments. Interestingly, in spite of having heavily infected root systems, Williams plants consistently had fewer symptoms on aerial parts than the other compatible interactions tested when inoculated with Ont-7-1 (Fig. 3).

Identification of partial (horizontal) resistance in soybean lines. Soybean cultivars of different backgrounds, from different sources and with known or unknown levels of horizontal resistance, were assayed in the recirculating system for the purpose of determining if the assay could discriminate phenotypes of partial resistance. In order to make sure that cases of vertical resistance did not bias the results, the hydroponic solutions were inoculated with a mixture of three isolates combining all pathotypes of possible Rps genes present in the material tested. Among the 59 lines tested, five classes, ranging from high partial resistance (class 1) to no partial resistance (class 5), could be discriminated (Fig. 4). Among them, seven displayed a very high level of resistance (class 1$)$, while nearly half of them $(42 \%)$ were found to have limited levels of horizontal resistance and ranked in classes 4 and 5 (Table 4). Among control cultivars used in this study, L49-4091 (Rps2) and Misty, with no known resistance, were promptly killed by the mixture of $P$. sojae and ranked in class 5. On the other hand, PI449459 and Jack showed an expected strong level of resistance. For its part, Conrad only showed an intermediate level of partial resistance (Table 4).
A
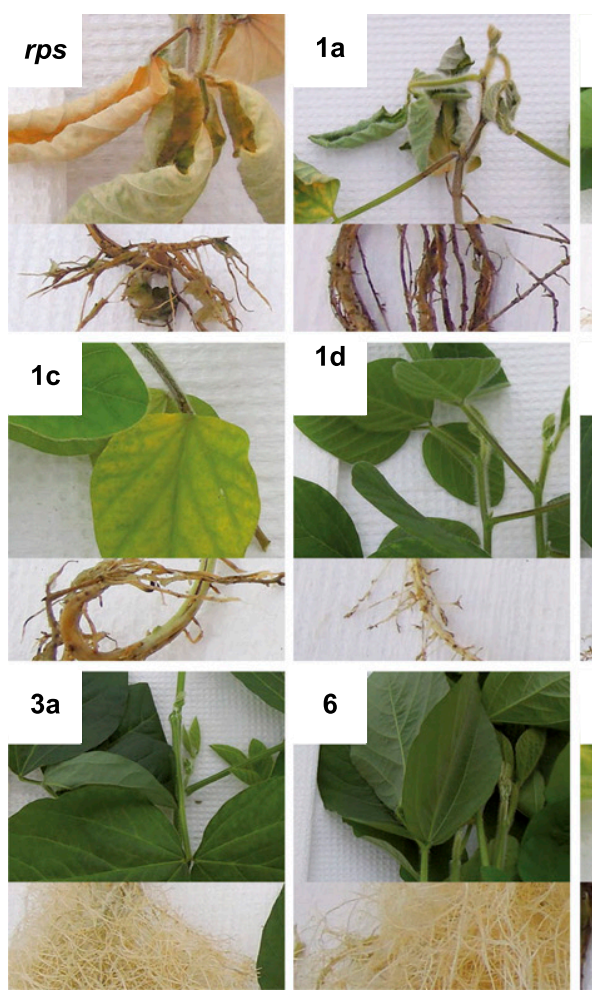

B

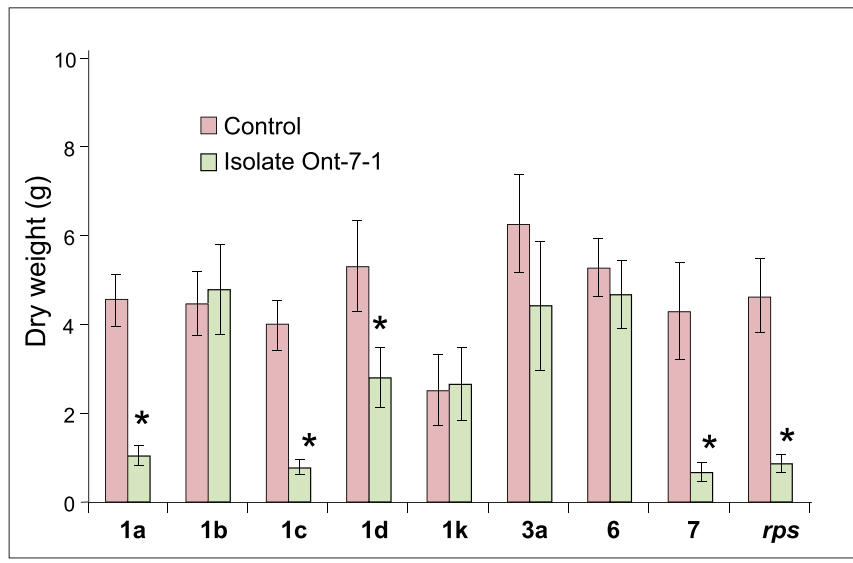

C
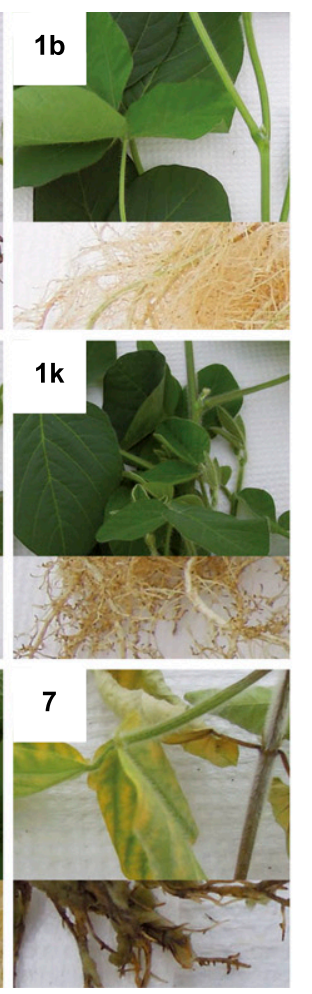
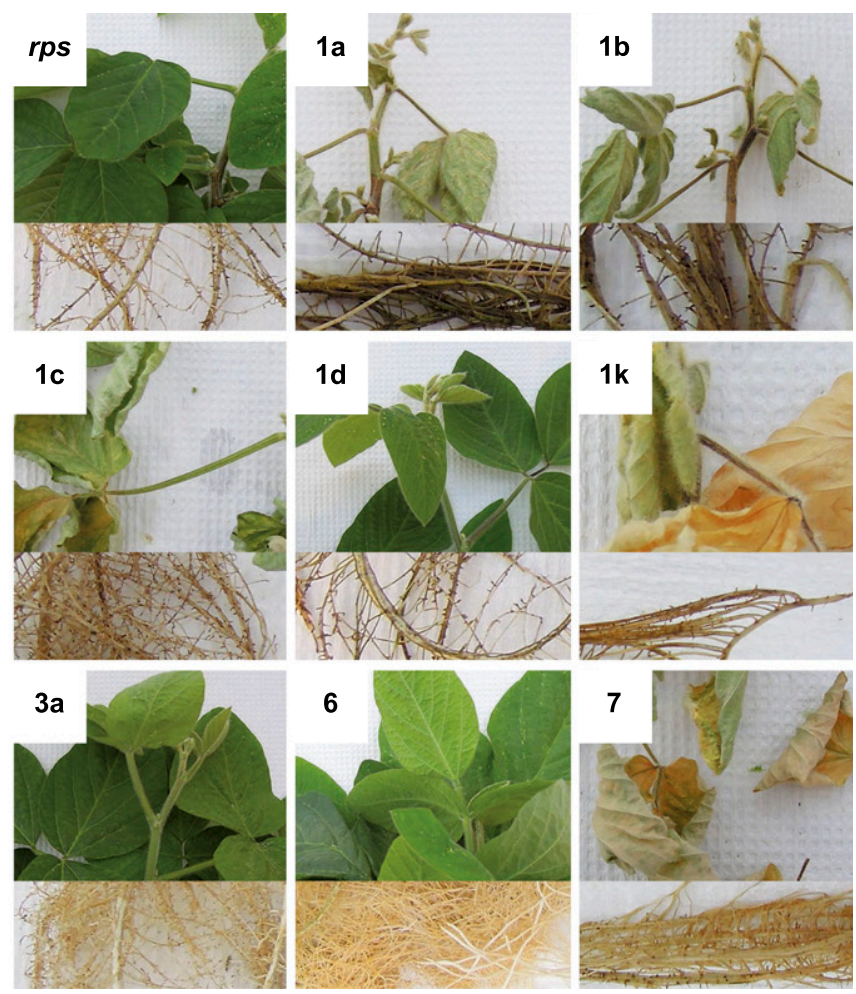

D

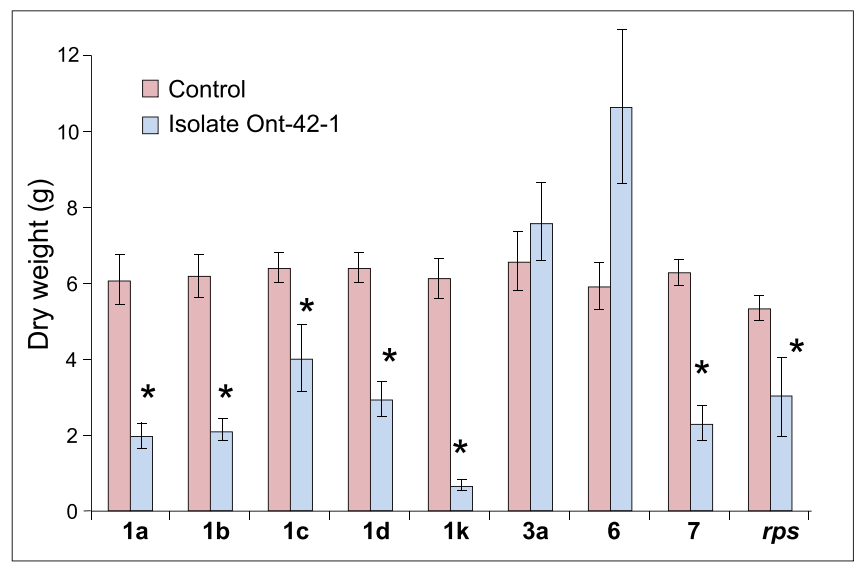

Fig. 1. Phenotypic responses and plant dry weight of eight common soybean differentials, L75-6141 » (Rps1a), L77-1863 (Rps1b), L75-3735 (Rps1c), Haro1672 (Rps1d, Rps7), Haro15 (Rps1k), L83-570 (Rps3a), L89-1581 (Rps6), and L93-3258 (Rps7), and Williams (rps) inoculated in a recirculating hydroponic system with zoospores of Phytophthora sojae; $\mathbf{A}$ and $\mathbf{B}$, isolate Ont-7-1 (vir 1a, 1c, 1d, 7); and $\mathbf{C}$ and $\mathbf{D}$, isolate Ont-42-1 (vir 1a, 1b, 1c, 1d, 1k, 7). In $\mathbf{B}$ and $\mathbf{D}$, bars represent standard errors from the mean ( $n=8$ ). Interactions are considered compatible when values, indicated with an asterisk $\left(^{*}\right)$, are significantly smaller than the control according to Dunnett test $(P<0.05)$. 
Hydroponic assays in miniature systems. When plants were inoculated in a hydroponic solution in containers rather than in a recirculating solution, disease symptoms could be observed on the roots as early as $5 \mathrm{dpi}$, and disease progression occurred more quickly than in the recirculating systems. Typical symptoms of $P$. sojae infection were observed both on roots and aerial parts and many plants died between 7 and 14 dpi (Fig. 5A). Phenotypic responses obtained for the eight differentials and Williams were in line with the expected compatible or incompatible interaction with isolate Ont-42-1 (1a, 1b, 1c, 1d, 1k, 7) (Fig. 5B), thus indicating that the smaller hydroponic system was as reliable as the recirculating system for studying the interaction between $P$. sojae and soybean.

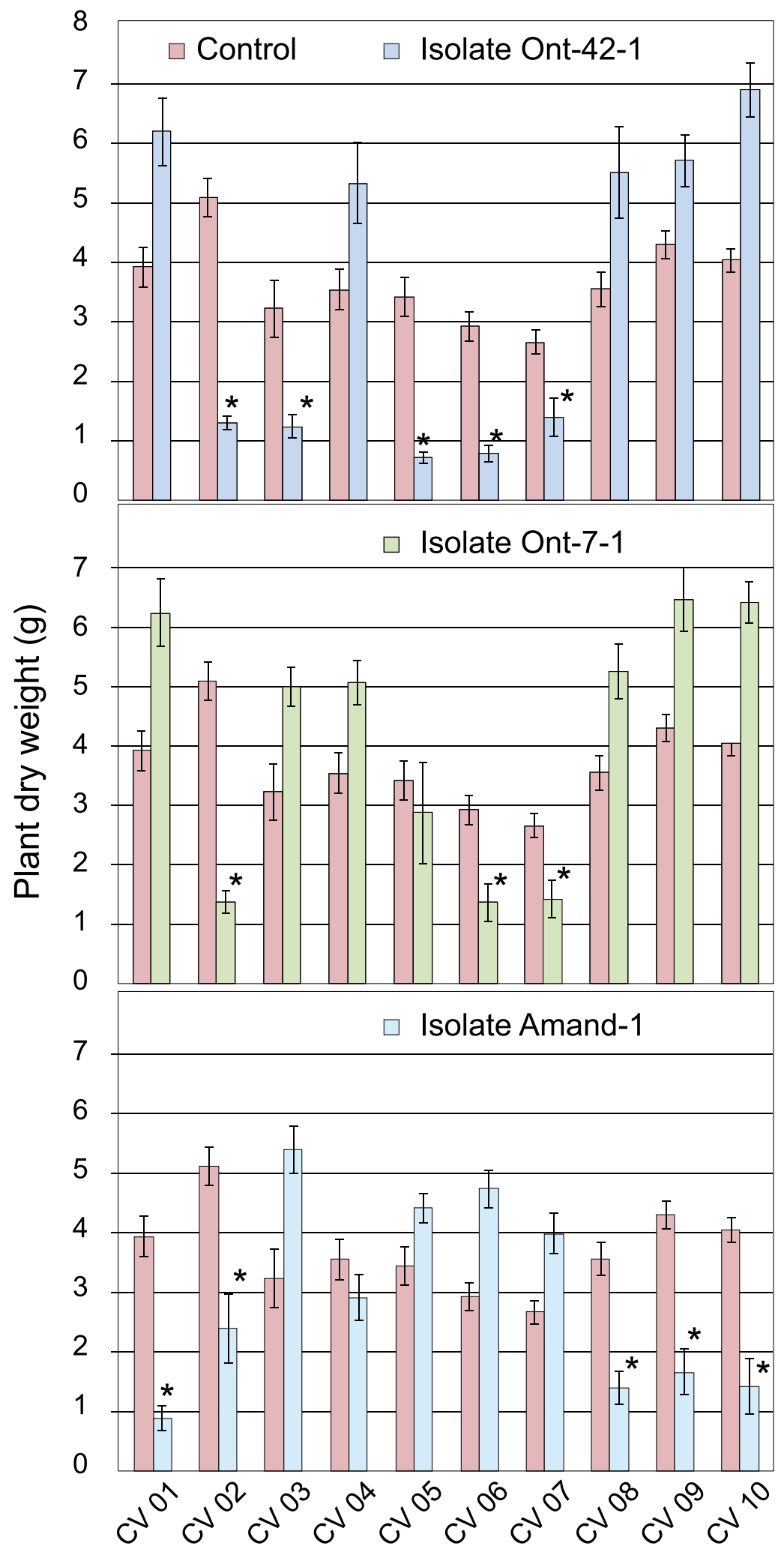

Fig. 2. Average dry weight of plants of 10 soybean commercial lines inoculated in a recirculating hydroponic system with zoospores of three isolates of Phytophthora sojae. Bars represent standard errors from the mean $(n=8)$. Interactions are considered compatible when values, indicated with an asterisk $\left(^{*}\right)$, are significantly smaller than the control according to Dunnett test $(P<0.05)$. 
When the miniature system was used for the detection of horizontal resistance with four different soybean lines, root symptoms and plant development showed discriminating patterns at $21 \mathrm{dpi}$ (Fig. 6). For instance, plants of PI449459 displayed a sizeable difference in size when compared with the susceptible lines Harosoy and Misty. For its part, QS5091.50J did not show a good level of resistance, even though its aerial parts were not as affected as those of Harosoy and Misty. In terms of dry weight, PI449459 averaged $0.95 \mathrm{~g}$ compared with 0.35, 0.37, and 0.47 g for Harosoy, Misty, and QS5091.50J, respectively.

\section{Discussion}

In this study, we report on a hydroponic bioassay that offers accurate and reproducible phenotyping of Phytophthora sojae pathotypes, and both vertical and horizontal resistance in soybean lines by overcoming many of the limitations encountered in other assays. The basic premise of the advantage of this bioassay is based on the fact that it reproduces the natural course of infection of $P$. sojae, since zoospores are allowed to infect roots immersed in water. As such, $P$. sojae can properly express its virulence/avirulence factors, and soybean its resistance genes, whether they are major Rps genes or QTLs involved in partial resistance. It thus provides a new tool for breeders and scientists working to develop or breed soybean lines that are better adapted to resist the multiple pathotypes reported in $P$. sojae isolates.

As a first validation, our results have clearly shown that the phenotypic responses of the eight differentials tested were in concordance with the pathotypes of the two isolates tested. The dry weight measure was a reliable quantitative variable to discriminate between the resistant and susceptible phenotypes, while a qualitative observation of the plants, and in particular the roots, was an equally reliable indication

Table 3. Comparison between phenotypic response obtained and expected following inoculation in a recirculating hydroponic system with zoospores from three isolates of Phytophthora sojae on 10 soybean lines carrying different Rps genes

\begin{tabular}{|c|c|c|c|c|c|}
\hline \multirow{2}{*}{$\begin{array}{l}\text { Soybean } \\
\text { line }\end{array}$} & $\begin{array}{l}\text { Isolate Ont-42-1; pathotype (vir } \\
\text { factors) } 1 \mathrm{a}, 1 \mathrm{~b}, 1 \mathrm{c}, 1 \mathrm{~d}, 1 \mathrm{k}, 7\end{array}$ & $\begin{array}{l}\text { Isolate Ont-7-1; pathotype } \\
\text { (vir factors) 1a, 1c, 1d, } 7\end{array}$ & $\begin{array}{l}\text { Isolate Amand-1; pathotype } \\
\text { (vir factors) 1a, 3a, 6, } 7\end{array}$ & \multirow[b]{2}{*}{ Possible genotypes } & \multirow{2}{*}{$\begin{array}{l}\text { Confirmed } \\
\text { genotype }\end{array}$} \\
\hline & \multicolumn{3}{|c|}{ Phenotypic response obtained / Phenotypic response expected } & & \\
\hline $\mathrm{Cv} 1$ & $\mathrm{R} / \mathrm{R}$ & $\mathrm{R} / \mathrm{R}$ & $\mathrm{S} / \mathrm{S}$ & Rps3a, Rps6 & Rps6 \\
\hline Cv2 & $\mathrm{S} / \mathrm{S}$ & $\mathrm{S} / \mathrm{S}$ & $\mathrm{S} / \mathrm{S}$ & Rps1a, rps & Rps1a \\
\hline Cv3 & $\mathrm{S} / \mathrm{S}$ & $\mathrm{R} / \mathrm{R}$ & $\mathrm{R} / \mathrm{R}$ & Rps $1 \mathrm{~b}, R p s 1 \mathrm{k}$ & Rps $1 \mathrm{k}$ \\
\hline Cv4 & $\mathrm{R} / \mathrm{R}$ & $\mathrm{R} / \mathrm{R}$ & $\mathrm{R} / \mathrm{R}$ & $R p s 1 \mathrm{c}+3 \mathrm{a}, \operatorname{Rps} 1 \mathrm{~d}+3 \mathrm{a}$ & $\operatorname{Rps} 1 \mathrm{c}+3 \mathrm{a}$ \\
\hline Cv5 & $\mathrm{S} / \mathrm{S}$ & $\mathrm{R} / \mathrm{R}$ & $\mathrm{R} / \mathrm{R}$ & Rps $1 \mathrm{~b}, \operatorname{Rps} 1 \mathrm{k}$ & Rps $1 \mathrm{k}$ \\
\hline Cv6 & $\mathrm{S} / \mathrm{S}$ & $\mathrm{S} / \mathrm{S}$ & $\mathrm{R} / \mathrm{R}$ & Rps $1 \mathrm{c}$, Rps $1 \mathrm{~d}$ & Rps $1 \mathrm{c}$ \\
\hline Cv7 & $\mathrm{S} / \mathrm{S}$ & $\mathrm{S} / \mathrm{S}$ & $\mathrm{R} / \mathrm{R}$ & Rps $1 \mathrm{c}$, Rps $1 \mathrm{~d}$ & Rps $1 \mathrm{c}$ \\
\hline Cv8 & $\mathrm{R} / \mathrm{R}$ & $\mathrm{R} / \mathrm{R}$ & $\mathrm{S} / \mathrm{S}$ & Rps3a, Rps6 & Rps6 \\
\hline Cv9 & $\mathrm{R} / \mathrm{R}$ & $\mathrm{R} / \mathrm{R}$ & $\mathrm{S} / \mathrm{S}$ & Rps3a, Rps6 & Rps3a \\
\hline Cv10 & $R / R$ & $\mathrm{R} / \mathrm{R}$ & $\mathrm{S} / \mathrm{S}$ & Rps3a, Rps6 & Rps6 \\
\hline
\end{tabular}
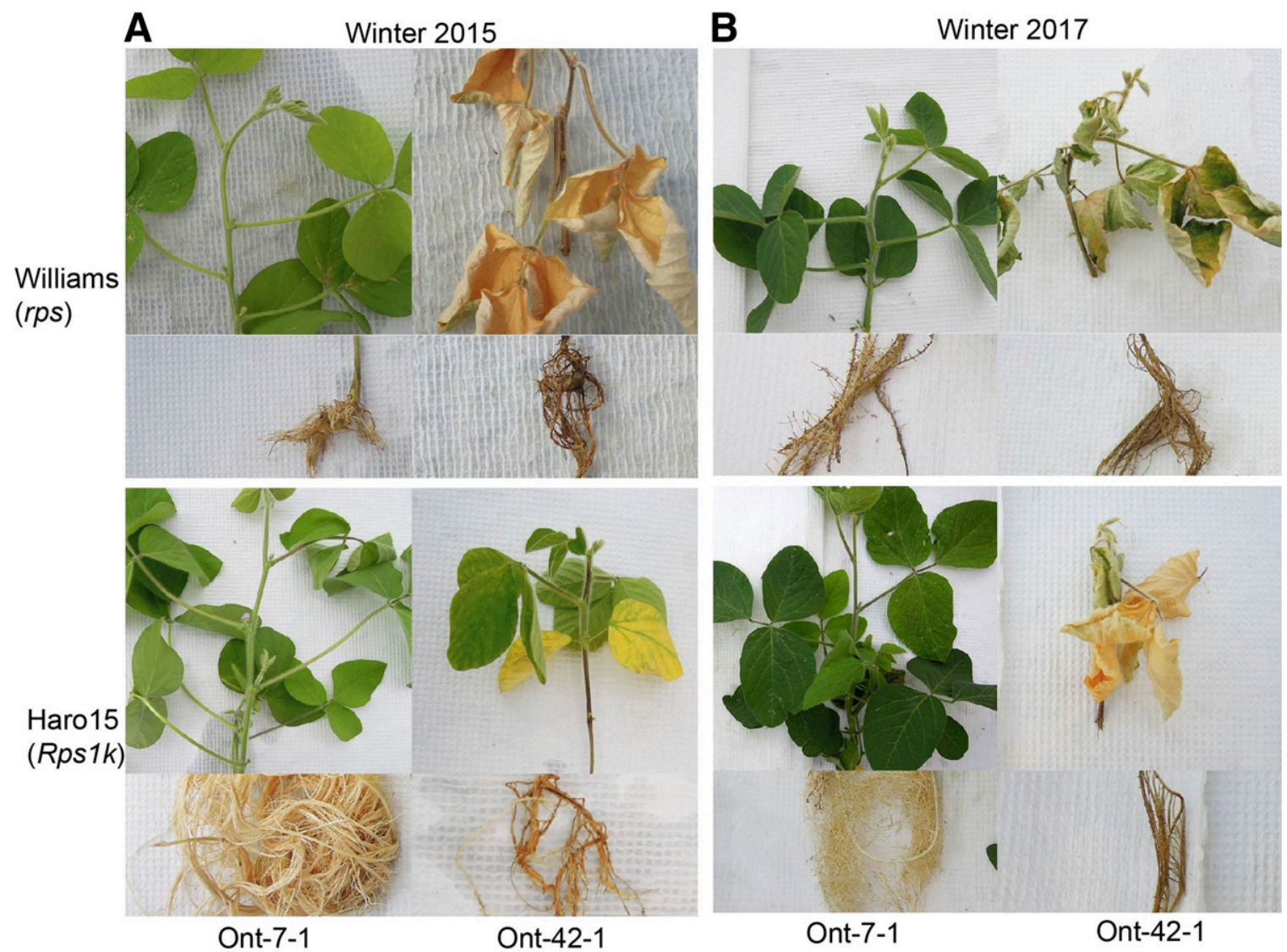

Fig. 3. Phenotypic responses of cvs Williams and Haro15 (Rps1k) inoculated in a recirculating hydroponic system in A, winter 2015, and B, winter 2017 with zoospores of the same two isolates of Phytophthora sojae, Ont-7-1 (vir 1a, 1c, 1d, 7); and Ont-42-1 (vir 1a, 1b, 1c, 1d, 1k, 7) following repeated subcultures of the isolates between the experiments. 
of the response. Admittedly, setting up the recirculating system is more cumbersome than the hypocotyl assay, but the bioassays used as few as four plants per treatment and did not result in the type of intermediate responses that often plague the hypocotyl assay (Jackson et al. 2004; Xue et al. 2015). However, the responses observed for both isolates with Rps1d yielded phenotypes that suggest either a lesser virulence or an imperfect gene for gene interaction given the contrast between the symptoms observed on roots versus aerial parts. In fact, isolate Ont-42-1 was originally phenotyped as avirulent against Rps 1d, only to be reclassified with virulence factor $1 \mathrm{~d}$ when retested (G. Marchand, unpublished). Our own data support the latter classification. In the future, it would be interesting to expand the comparisons between the two approaches to determine what or if Rps genes are seemingly more or less expressed in one assay or the other, and how it actually relates to a more accurate phenotype based on the presence/absence of the gene.

Accurate evaluation of the presence/expression of a given $R p s$ gene in a soybean line is of primary importance for breeders, farmers, and seed companies in their efforts to minimize losses to P. sojae. For this reason, we wanted to determine if the hydroponic assay was just as reliable in identifying Rps genes as pathotypes. In collaboration with the seed company Prograin Semences Inc., we set up a blind testing of 10 soybean lines that contained different Rps genes. These experiments revealed several interesting features of the bioassay. As a first observation, the 40 interactions tested (10 lines $\times$ four treatments) and scored on the basis of plant dry weight yielded contrasting responses that allowed an unequivocal classification of a resistant or susceptible phenotype, whether or not it matched the Rps gene predicted to be present in the tested lines. As it turned out, the bioassay accurately predicted all Rps genes present in the lines, as confirmed by Prograin, even in the case of gene pyramiding (cv4) that offered protection against all isolates. The bioassay could thus validate or predict accurately how soybean lines should respond to the presence of $P$. sojae isolates with known virulence factors in a given area. An interesting component of the bioassay was the observation that most incompatible interactions actually exceeded the controls in terms of dry weight. In a way, this provided an easy way to classify the interactions, but our efforts to explain this phenomenon remain speculative. We have been unable to find in the literature or elsewhere reports to the effect that interaction of soybean with avirulent isolates of $P$. sojae would stimulate growth of the plants. On the other hand, cases of plant growth promoting fungi (PGPF) and PGPR are well described (Bent 2006) and one can hypothesize that "non-pathogenic" P. sojae releases factors promoting soybean growth. An easier explanation may be that, during the course of the bioassays, compatible interactions result in dead or dying plants, thus leaving more nutrients for the resistant plants in the recirculating systems.

The hypocotyl assay is often criticized for its lack of reproducibility over time (Jiang et al. 2017; Schmitthenner et al. 1994). This phenomenon, if somewhat preventable through storage of isolates in liquid nitrogen (Tooley 1988), remains puzzling. Genetic drift/instability, epigenetic modifications, isolate mixtures, and/or polyploidy have all been proposed to explain the different expression of pathotypes obtained over time (Dorrance 2013). In an attempt to determine if the hydroponic bioassay was equally subjected to this variability, two isolates kept at room temperature were phenotyped five times over a period of two years. Interestingly, we never observed a change in the virulence pattern of the isolates over the tested periods. In a previous study Schmitthenner et al. (1994) observed a level of variation within races over time that they attributed to race variability from successive cultures, or race mixtures from diseased tissues. However, inoculation procedures all relied on the hypocotyl assay with mycelium slurry and some isolates were more prone than others to display different virulence patterns. From our observations, albeit limited to two isolates, it appears that the generation of fresh zoospores for each inoculation maintains the virulence pattern of the isolates. If it is indeed the case, and more isolates should be tested to ascertain this possibility, this would resolve a major issue with phenotyping of both $P$. sojae isolates and soybean Rps genes that has hampered studies of the P. sojaesoybean interaction.

In the context of the rapid evolution of pathotypes in $P$. sojae, it is well known that the reliability of Rps genes in soybean is temporary
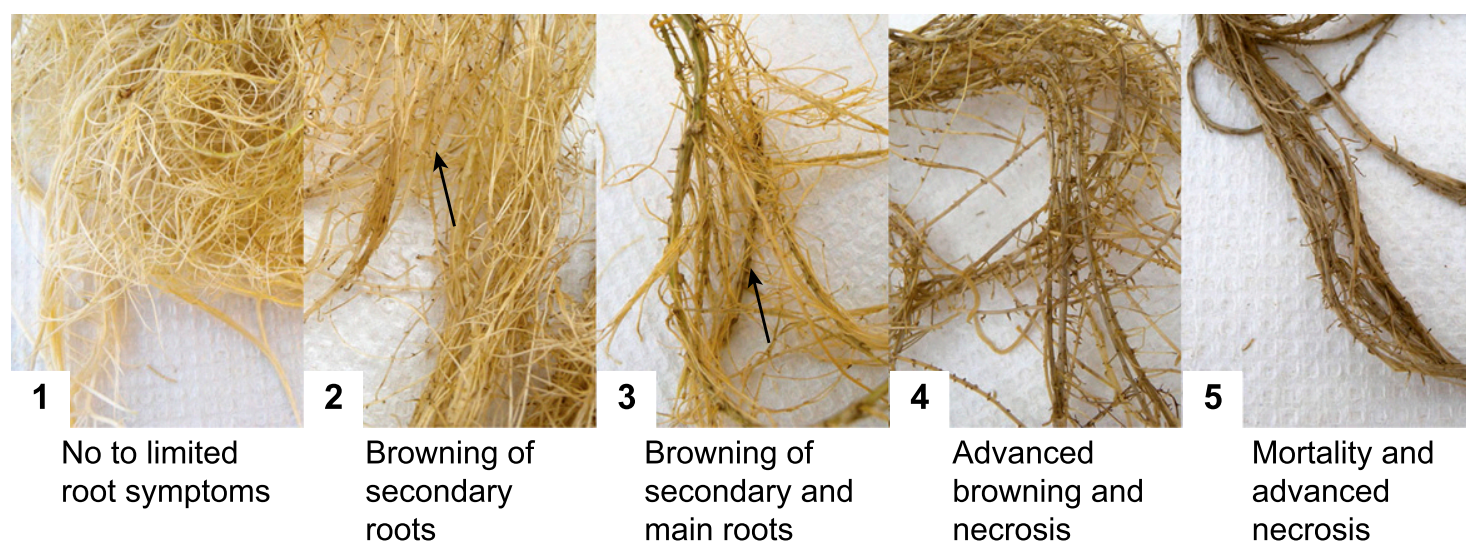

Fig. 4. Spectrum of root symptoms divided into five distinct classes following inoculation of 64 soybean lines evaluated for horizontal resistance in a recirculating hydroponic system inoculated with zoospores of three isolates of Phytophthora sojae carrying all possible pathotypes against Rps genes present in tested lines. In 2, black arrow indicates necrotic lesions on secondary roots; and in 3 , black arrow indicates necrosis of main root.

Table 4. Classification into five distinct classes based on extent of root symptoms of 64 soybean lines evaluated for horizontal resistance following inoculation in a recirculating hydroponic system with zoospores of three isolates of Phytophthora sojae carrying all possible pathotypes against $R p s$ genes present in tested lines. See Fig. 4 for representative phenotype of each class.

\begin{tabular}{|c|c|c|c|c|c|}
\hline $\begin{array}{l}\text { Degree of partial } \\
\text { resistance and } \\
\text { symptoms (class) }\end{array}$ & $\begin{array}{c}\text { Very high. No to } \\
\text { limited root symptoms } \\
\text { (1) }\end{array}$ & $\begin{array}{l}\text { High. Browning of } \\
\text { secondary roots (2) }\end{array}$ & $\begin{array}{l}\text { Moderate. Browning of } \\
\text { secondary and main } \\
\text { roots }(3)\end{array}$ & $\begin{array}{l}\text { Low. Advanced } \\
\text { browning and necrosis } \\
\text { (4) }\end{array}$ & $\begin{array}{l}\text { Very low. Mortality } \\
\text { and advanced necrosis } \\
(5)\end{array}$ \\
\hline Cultivar & $\begin{array}{l}\text { L3 ; L17 ; L20 ; L26 ; } \\
\text { L27 ; L36; L48; }\end{array}$ & $\begin{array}{l}\text { L6 ; L11; L13 ; L19; } \\
\text { L21; L31; L35; L51; } \\
\text { L52; L58; PI449459; } \\
\text { Jack }\end{array}$ & $\begin{array}{l}\text { L5 ; L7 ; L16; L18; L24; } \\
\text { L29; L30; L32; L39; } \\
\text { L40; L41; L44; L47; } \\
\text { L50; L54; L55; L57; } \\
\text { Conrad }\end{array}$ & $\begin{array}{l}\text { L2 ; L10 ; L22; L33; } \\
\text { L37; L38; L42; L43; } \\
\text { L45; L53; L56; }\end{array}$ & $\begin{array}{l}\text { L1 ; L4 ; L8 ; L9 ; L12; } \\
\text { L14 ; L15 ; L23; L25; } \\
\text { L28; L34; L46; L49; } \\
\text { L59; L49-4091 (Rps2); } \\
\text { Misty }\end{array}$ \\
\hline
\end{tabular}


A

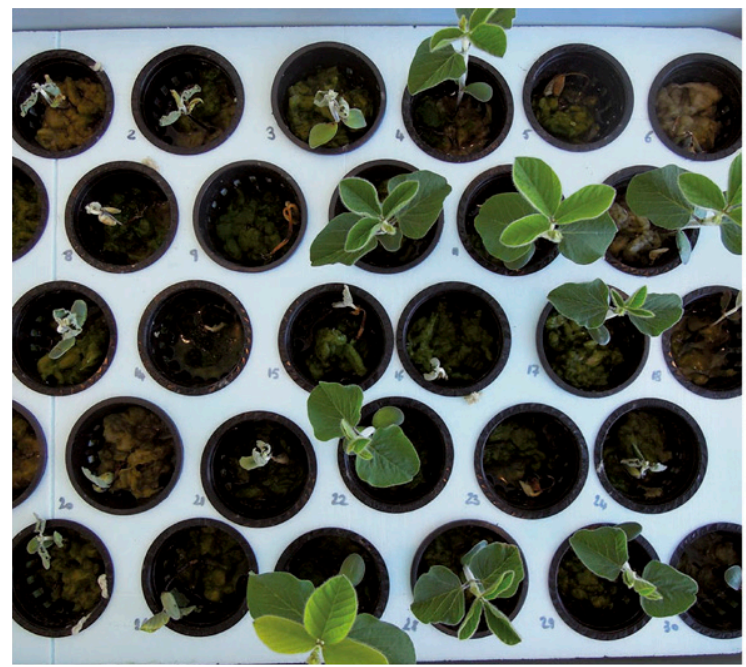

$1 \mathrm{c}$

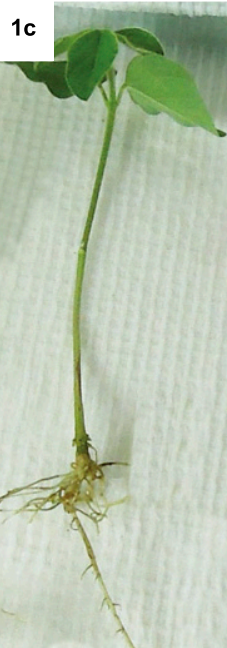

$1 d$

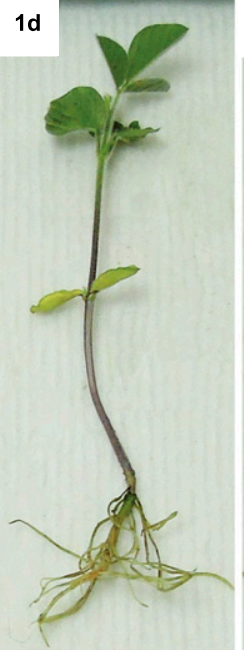

B

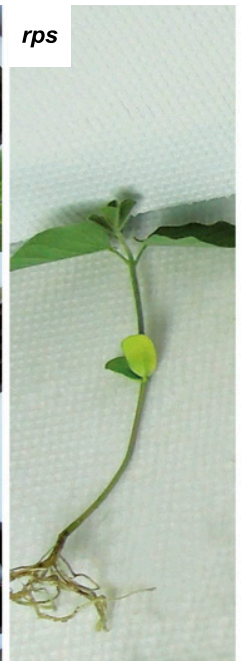

$1 \mathrm{k}$
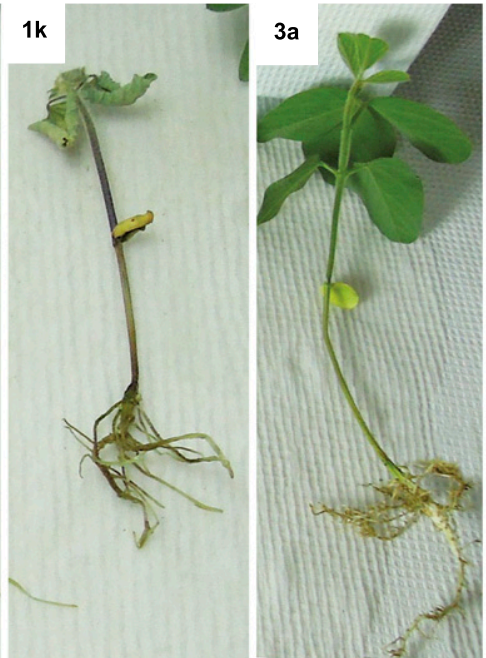

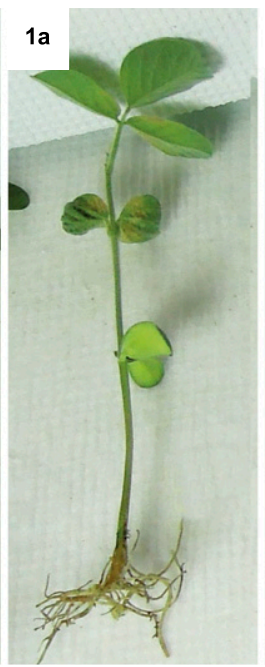

$1 b$
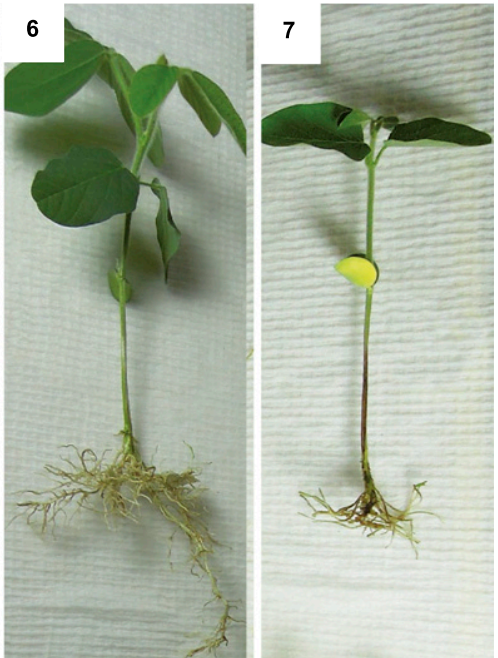

Fig. 5. A, Development of 14-day-old soybean plants and B, phenotypic responses of eight common soybean differentials, L75-6141 (Rps1a), L77-1863 (Rps1b), L75-3735 (Rps1c), Haro1672 (Rps1d, Rps7), Haro15 (Rps1k), L83-570 (Rps3a), L89-1581 (Rps6) and L93-3258 (Rps7), and Williams (rps) inoculated in a miniature hydroponic system with zoospores of Phytophthora sojae isolate Ont-42-1 (vir 1a, 1b, 1c, 1d, 1k, 7).

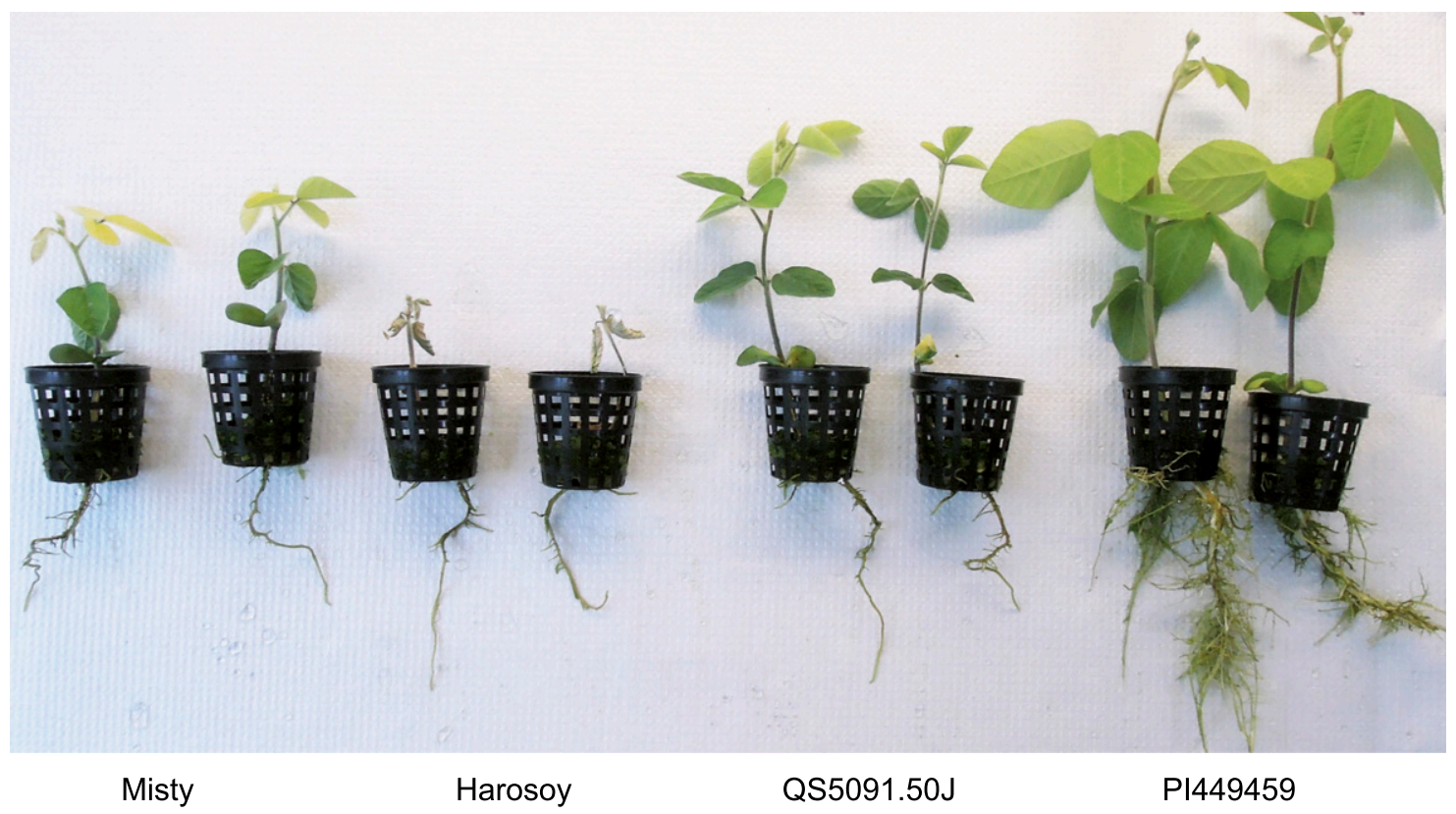

Fig. 6. Phenotypic responses of 21-day-old soybean plants cvs. Misty, Harosoy, QS5091.50J, and PI449459 inoculated in a miniature hydroponic system with zoospores of Phytophthora sojae isolates Ont-42-1, Ont-7-1, and Amand-1 showing an expected stronger resistance and development of PI449459 plants. 
(Dorrance 2013; Xue et al. 2015). For this reason, horizontal resistance is a component of a desirable strategy to supplement Rps genes on the basis that it is theoretically effective against all isolates (Sugimoto et al. 2012). On the other hand, exploitation of horizontal resistance and discovery of suitable QTLs have been hindered by the lack of a reproducible assay for phenotyping purposes. Given that the hypocotyl inoculation method can basically only reveal vertical resistance, phenotyping for horizontal resistance must rely on additional assays, often consider several variables (Schneider et al. 2016), and somehow eliminate the expression of vertical resistance. This usually entails trying to test with $P$. sojae isolates containing as many pathotypes as possible (Schneider et al. 2016) or trying to combine pathotypes of several isolates in a mycelium slurry (Jiang et al. 2017; Matthiesen et al. 2016; Stewart and Robertson 2012). As demonstrated in this study, the hydroponic assay offers the versatility to overcome those limitations. For instance, a major advantage resides in the possibility to inoculate soybean plants with zoospores from several isolates simultaneously as a way to cover all Rps genes that could be present in the tested material. This way, one can ensure that all forms of expressed resistance are indeed attributable to partial (horizontal) resistance.

Based on our observations, the inoculations led to a fairly wide spectrum of responses that certainly indicates that different levels of horizontal resistance are present within the soybean germplasm that was evaluated. Furthermore, our results tend to indicate that the respective responses obtained with the cultivars tested are in line with their known or expected level of horizontal resistance. For instance, Misty with no known resistance was ranked in the lowest group and its root system was heavily degraded. Interestingly, L49-4091 carrying the elusive Rps 2 was also ranked in the lowest group a result contradicting somewhat its statute as a root resistance gene providing incomplete resistance (Mideros et al. 2007). On the other hand, Jack, often reported to have a good level of resistance (Mideros et al. 2007; Guérin et al. 2014), and PI449459, reported to display strong horizontal resistance (Jia and Kurle 2008), did tolerate very well the presence of $P$. sojae and ranked in the second-best group. Among the other lines tested, some displayed near complete levels of resistance and should represent an excellent source of partial resistance for breeding purposes. Surprisingly, Conrad, a staple reference for horizontal resistance (Sugimoto et al. 2012), only fared moderately in the bioassay. Given that several other lines showed better levels of resistance, and the fairly accurate ranking of specific cultivars based on their expected response, we conclude that this bioassay can uncover new sources of horizontal resistance.

While the hydroponic bioassay in recirculating systems proved extremely reliable for the purpose of studying the $P$. sojae-soybean interaction, its requirements in terms of greenhouse facilities, materials for recirculating systems, costs, and human resources are a limiting factor for routine applications and small-scale experiments. For this reason, we wanted to investigate the possibility of maintaining the basic principles conferring its efficiency, and reducing its complexity. Our results have shown that by growing plants in a small plastic tank containing a hydroponic solution inoculated with zoospores of $P$. sojae, it was possible to reproduce the exact same results as in recirculating solutions for the identification of the pathotypes. The phenotypes are manifest in a period of 7 days and as many as 30 plants can be tested in a simple 10-liter container. With only three or four plants necessary per differential, one can thus determine the pathotype of an isolate with seven or eight differentials in a single container with maximum reproducibility since all plants are inoculated from the same homogeneous zoospore solution. However, it remains important to ensure that isolates are maintained in conditions conducive for zoospore production. In the same manner, the miniature system allowed discrimination of several lines for horizontal resistance. The differences were easily discernible by a simple observation of the root systems and could be quantified by plant dry weight. On the other hand, the system may require a duplicate set of control plants when testing plants of different genetic background that may not respond the same way to hydroponic culture. This would entail measuring plant dry weight of both control and treated plants to obtain reliable comparative values. Whether testing for vertical or horizontal resistance, it is also important to maintain reference cultivars expressing opposite responses to ascertain that the bioassay is dependable.

In conclusion, we have developed a new and reproducible hydroponics assay for the study of the $P$. sojae-soybean interaction that can detect both vertical and horizontal resistance, and pathotypes of $P$. sojae through a single homogenous inoculation procedure reproducing the natural course of infection with zoospores. This method should greatly facilitate current and future efforts in breeding for soybean resistance and in genomic studies aimed at identifying resistance genes in soybean and virulence factors in P. sojae.

\section{Acknowledgments}

We would like to thank the following partners for their funding: Genome Canada, Génome Québec, Ministère de l'Économie, Innovation et Exportation du Québec, Western Grains Research Foundation, Canadian Field Crop Research Alliance, Institut de Biologie Intégrative et des Systèmes (IBIS-ULaval), Centre de recherche sur les grain (CEROM), Agriculture and Agri-Food Canada, the University of Guelph, Semences Prograin, Syngenta, Sevita Genetics, la Coop Fédérée Producteurs de grains du Québec, Grain Farmers of Ontario, Manitoba Pulse and Soybean Growers, Saskatchewan Pulse Growers, Réseau d'avertissements phytosanitaires, and Empresa Brasileira de Pesquisa Agropecuária (EMBRAPA). This work was further supported by grants from the Natural Sciences and Engineering Research Council of Canada and the Canada Research Chairs Program to RRB. We thank Ariane Belzile for technical assistance.

\section{Literature Cited}

Abeysekara, N. S., Matthiesen, R. L., Cianzio, S. R., Bhattacharyya, M. K., and Robertson, A. E. 2016. Sources of partial resistance against Phytophthora sojae in soybean PI399036. Crop Sci. 56:2322-2335.

Anderson, T. R., and Buzzell, R. I. 1992. Inheritance and linkage of the Rps 7 gene for resistance to Phytophthora rot of soybean. Plant Dis. 76:958-959.

Arsenault-Labrecque, G., Menzies, J. G., and Bélanger, R. R. 2012. Effect of silicon absorption on soybean resistance to Phakopsora pachyrhizi in different cultivars. Plant Dis. 96:37-42.

Bent, E. 2006. Induced systemic resistance mediated by plant growth-promoting Rhizobacteria (PGPR) and Fungi (PGPF). Pages 225-258 in: Multigenic and Induced Systemic Resistance in Plants. S. Tunzun and E. Bent, eds. Springer, New York, NY.

Bernard, R. L., Smith, P. E., Kaufmann, M. J., and Schmitthenner, A. F. 1957 Inheritance of resistance to Phytophthora root and stem rot in soybean. Agron. J. 49:391

Dorrance, A. 2013. Phytophthora sojae on soybean. Pages 79-86 in: Phytophthora: A Global Perspective. K. Lamour, ed. CABI, Wallingford, Oxfordshire, UK.

Dorrance, A. E., Berry, S. A., Anderson, T. R., and Meharg, C. 2008. Isolation, storage, pathotype characterization, and evaluation of resistance for Phytophthora sojae in soybean. Plant Health Prog. doi:10.1094/PHP-2008-0118-01-DG

Dorrance, A. E., Jia, H., and Abney, T. S. 2004. Evaluation of soybean differentials for their interaction with Phytophthora sojae. Plant Health Prog. doi:10.1094/ PHP-2004-0309-01-RS

Eye, L. L., Sneh, B., and Lockwood, J. L. 1978. Inoculation of soybean seedlings with zoospores of Phytophthora megasperma var. sojae for pathogenicity and race determination. Phytopathology 68:1769-1773.

Guérin, V., Lebreton, A., Cogliati, E. E., Hartley, S. E., Belzile, F., Menzies, J. G., and Bélanger, R. R. 2014. A zoospore inoculation method with Phytophthora sojae to assess the prophylactic role of silicon on soybean cultivars. Plant Dis. 98:1632-1638.

Guy, S. O., Oplinger, E. S., and Grau, C. R. 1989. Response to metalaxyl applied in furrow and as seed treatment. Agron. J. 81:529-532.

Haas, J. H., and Buzzell, R. I. 1976. New races 5 and 6 of Phytophthora megasperma var. sojae and differential reactions of soybean cultivars for races 1 and 6. Phytopathology 66:1361-1362.

Hsu, S. C., and Lockwood, J. L. 1984. Biological control of Phytophthora root rot of soybean by Hyphochytrium catenoides in greenhouse tests. Phytopathology 109:139-146.

Jackson, T. A., Kirkpatrick, T. L., and Rupe, J. C. 2004. Races of Phytophthora sojae in Arkansas soybean fields and their effects on commonly grown soybean cultivars. Plant Dis. 88:345-351.

Jia, H., and Kurle, J. E. 2008. Resistance and partial resistance to Phytophthora sojae in early maturity group soybean plant introductions. Euphytica 159: 27-34

Jiang, C. J., Sugano, S., Kaga, A., Lee, S. S., Sugimoto, T., Takahashi, M., and Ishimoto, M. 2017. Evaluation of resistance to Phytophthora sojae in soybean mini core collections using an improved assay system. Phytopathology 107: 216-223.

Kilen, T. C., and Keeling, B. L. 1977. Simultaneous screening of soybeans against three races of Phytophthora megasperma var. sojae. Crop Sci. 17:185-186.

Ko, W. H., Chase, L. L., and Kunimoto, R. K. 1973. Microsyringe method for determining concentration of fungal propagules. Phytopathology 63:1206-1207.

Matthiesen, R. L., Abeysekara, N. S., Ruiz-Rojas, J. J., Biyashev, R. M., Maroof, M. S., and Robertson, A. E. 2016. A method for combining isolates of 
Phytophthora sojae to screen for novel sources of resistance to Phytophthora stem and root rot in soybean. Plant Dis. 100:1424-1428.

McBlain, B. A., Hacker, J. K., Zimmerly, M. M., and Schmitthenner, A. F. 1991. Tolerance to Phytophthora rot in soybean: II. Evaluation of three tolerance screening methods. Crop Sci. 31:1412-1417.

McDonald, B. A., and Linde, C. 2002. Pathogen population genetics, evolutionary potential, and durable resistance. Annu. Rev. Phytopathol. 40:349-379.

Mideros, S., Nita, M., and Dorrance, A. E. 2007. Characterization of components of partial resistance, Rps2, and root resistance to Phytophthora sojae in soybean. Phytopathology 97:655-662.

Morrison, R. H., and Thorne, J. C. 1978. Inoculation of detached cotyledons for screening soybeans against two races of Phytophthora megasperma var. sojae. Crop Sci. 18:1089-1091.

Osburn, R. M., Milner, J. L., Oplinger, E. S., Smith, R. S., and Handelsman, J. 1995. Effect of Bacillus cereus UW85 on the yield of soybean at two field sites in Wisconsin. Plant Dis. 79:551-556.

Pazdernik, D. L., Hartman, G. L., Huang, Y. H., and Hymowitz, T. 1997. A greenhouse technique for assessing Phytophthora root rot resistance in Glycine max and Glycine soja. Plant Dis. 81:1112-1114.

Sahoo, D. K., Abeysekara, N. S., Cianzio, S. R., Robertson, A. E., and Bhattacharyya, M. K. 2017. A novel Phytophthora sojae resistance Rps 12 gene mapped to a genomic region that contains several Rps genes. PLoS One 12:e0169950.

Schmitthenner, A. F. 1985. Problems and progress in control of Phytophthora root rot of soybean. Plant Dis. 69:362-368.

Schmitthenner, A. F. 2000. Pages 39-42 in: Phytophthora rot of soybean. Compendium of Soybean Diseases, 4th Ed. American Phytopathological Society, St. Paul, MN.

Schmitthenner, A. F., Hobe, M., and Bhat, R. G. 1994. Phytophthora sojae races in Ohio over a 10-year interval. Plant Dis. 78:269-276.

Schneider, R., Rolling, W., Song, Q., Cregan, P., Dorrance, A. E., and McHale, L. K. 2016. Genome-wide association mapping of partial resistance to Phytophthora sojae in soybean plant introductions from the Republic of Korea. BMC Genomics 17:607.
Stewart, S., and Robertson, A. E. 2012. A modified method to screen for partial resistance to Phytophthora sojae in soybean. Crop Sci. 52:1181-1186.

Sugimoto, T., Aino, M., Sugimoto, M., and Watanabe, K. 2005. Reduction of Phytophthora stem rot disease on soybeans by the application of $\mathrm{CaCl}_{2}$ and $\mathrm{Ca}\left(\mathrm{NO}_{3}\right)_{2}$. J. Phytopathol. 153:536-543.

Sugimoto, T., Kato, M., Yoshida, S., Matsumoto, I., Kobayashi, T., et al. 2012 Pathogenic diversity of Phytophthora sojae and breeding strategies to develop Phytophthora-resistant soybeans. Breed. Sci. 61:511-522.

Sugimoto, T., Watanabe, K., Furiki, M., Walker, D. R., Yoshida, S., Aino, M., Kanto, T., and Irie, K. 2009. The effect of potassium nitrate on the reduction of Phytophthora stem rot disease of soybeans, the growth rate and zoospore release of Phytophthora sojae. J. Phytopathol. 157:379-389.

Tooley, P. W. 1988. Use of uncontrolled freezing for liquid nitrogen storage of Phytophthora species. Plant Dis. 72:680-682.

Tyler, B. M. 2007. Phytophthora sojae: root rot pathogen of soybean and model oomycete. Mol. Plant Pathol. 8:1-8.

Wagner, R. E., and Wilkinson, H. T. 1992. An aeroponics system for investigating disease development on soybean taproots infected with Phytophthora sojae. Plant Dis. 76:610-614.

Ward, E. W. B., Lazarovits, G., Unwin, C. H., and Buzzell, R. I. 1979. Hypocotyl reactions and glyceollin in soybeans inoculated with zoospores of Phytophthora megasperma var. sojae. Phytopathology 69:951-955.

Workneh, F., Yang, X. B., and Tylka, G. L. 1998. Effect of tillage practices on vertical distribution of Phytophthora sojae. Plant Dis. 82:1258-1263.

Xiao, K., Kinkel, L. L., and Samac, D. A. 2002. Biological control of Phytophthora root rots on alfalfa and soybean with Streptomyces. Biol. Control 23:285-295.

Xue, A. E., Marchand, G., Chen, Y., Zhang, S., Cober, E. R., and Tenuta, A. 2015. Races of Phytophthora sojae in Ontario, Canada, 2010-2012. Can. J. Plant Pathol. 37:376-383

Zhang, S., and Xue, A. G. 2010. Population biology and management strategies of Phytophthora sojae causing Phytophthora root and stem rots of soybean. Pages 318-328 in: Management of Fungal Plant Pathogens. A. Arya and A. Perelló. CABI, Wallingford, Oxfordshire, UK 